\title{
Quality of life in elderly patients following coronary artery bypass grafting
}

\author{
This article was published in the following Dove Press journal: \\ Patient Preference and Adherence \\ 14 March 2014 \\ Number of times this article has been viewed
}

\section{Ewelina Bak' \\ Czesław Marcisz ${ }^{2}$}

'Faculty of Health Sciences, University of Bielsko-Biała, Bielsko-Biała, ${ }^{2}$ Department of Gerontology and Geriatric Nursing, School of Health Sciences, Medical University of Silesia, Katowice, Poland
Correspondence: Ewelina Bak Faculty of Health Sciences, University of Bielsko-Biała, ul. Willowa 2, 43-300 Bielsko-Biała, Poland

Tel +4833827 9198

Email ewelina.bak76@wp.pl
Background: Surgical revascularization of the coronary arteries leads to changes in quality of life (QoL) for patients with coronary heart disease. The aim of this work was to monitor QoL, considering cognitive function, depression, and activities of daily living in elderly patients after coronary artery bypass grafting (CABG).

Methods: This study included 65 patients (29 women and 36 men) aged 61-74 years with stable coronary heart disease who underwent CABG. The control group included 29 women and 36 men aged 61-74 years who were not suffering from coronary heart disease. The questionnaires used in the study canvassed QoL (Nottingham Health Profile), cognitive function, depression, and basic and instrumental activities of daily living. The research was conducted before surgery and repeated 6 and 12 months after surgery.

Results: QoL was comparable between women and men and was lower than in the control group $(P<0.05)$. After $\mathrm{CABG}$, the values for particular domains of QoL improved more in men than in women. There was a reduction in the severity of depression 6 months after surgery in men and 12 months after surgery in women.

Conclusion: Elderly patients with coronary heart disease have decreased QoL, which normalizes in men and improves in women after CABG.

Keywords: coronary heart disease, depression, cognitive function, activities of daily living

\section{Introduction}

Cardiovascular disease is the most common cause of morbidity and mortality in developed countries, and controlling it is a major challenge for health care systems. The authors of the latest American Heart Association report predict a significant increase in the burden of cardiovascular disease in the USA by 2030, and a huge cost for its treatment. ${ }^{1,2}$ In developed countries, population aging will become a major cause of the increased incidence of cardiovascular disease. Reduction of the premature mortality associated with cardiovascular disease is possible in Poland and throughout the world. The scale of the problem has been highlighted in a number of randomized studies, including The National Cardiovascular Disease Prevention and Treatment Program (POLKARD) ${ }^{3}$ in Poland and the Japan Assessment of Pitavastatin and Atorvastatin In Acute Coronary Syndrome (JAPAN-ACS). ${ }^{4}$ The achievement of positive results in the treatment of patients suffering from coronary heart disease (CHD) is possible thanks to the common introduction of invasive procedures on the heart, particularly in the coronary arteries. These procedures are performed more and more often in elderly patients. ${ }^{5,6}$ Coronary artery bypass grafting (CABG) is mainly performed in elderly patients to reduce mortality and improve their quality of life (QoL). ${ }^{5}$ A significant 
theme in assessment of QoL in patients after CABG is the long-term outcomes of treatment. ${ }^{7,8}$ The research referring to evaluation of QoL after CABG has been inconclusive. In the majority of patients, QoL has improved after CABG, but often in a differentiated manner, depending on the gender of patients studied. ${ }^{9}$ A meta-analysis has shown that performing $\mathrm{CABG}$ in the elderly may be associated with significant improvements in QoL. ${ }^{10}$

The studies available have used various methods to assess QoL in patients after myocardial revascularization, which accounts for why the results obtained have not been consistent. ${ }^{11}$ The study patients were assessed for only some of the components of QoL and without inclusion of controls for comparison. Further, the research concerning QoL in patients with CHD treated invasively, especially elderly patients, has not been conducted in a sufficiently comprehensive way, and has not simultaneously taken into account the determinants of QoL, such as activities of daily living, the patient's emotional state, cognitive function, or depression. The research to date indicates that depression increases the risk of morbidity and mortality after cardiac surgery. ${ }^{12,13}$ The need to conduct further comprehensive research into the QoL of patients after CABG appears to be warranted. This work examined the level of QoL, taking into consideration cognitive functioning, depression, and ability to perform basic and independent activities of daily living, in elderly patients with CHD treated surgically by CABG.

\section{Materials and methods}

This study included 65 patients with CHD selected randomly from patients hospitalized in 2009 at the Department of Cardiovascular Surgery and Transplantology, Jagiellonian University Medical College, Krakow, Poland. The study patients comprised 29 women and 36 men aged $61-74$ years. Eligibility for CABG was determined on the basis of coronary angiography. At least 50\% stenosis of the luminal diameter of the left main coronary artery trunk and at least $70 \%$ stenosis of other arteries was considered to be hemodynamically significant. Inclusion criteria for the study group were elective admission to a cardiac surgery department with stable CHD and coronary lesions, eligible only for surgical revascularization, left ventricular ejection fraction $>40 \%$, and ability to provide informed consent. Exclusion criteria were an acute coronary syndrome during the previous 6 months, combination of CABG with other cardiac surgery, and hearing or vision impairment preventing completion of the questionnaires. After taking into account the inclusion and exclusion criteria, the research was carried out in patients who were successively admitted to hospital. This ensured random patient selection, so the study sample may be regarded as representative.

All statistical tests were performed at a significance level of 0.05 . This implies that the sample size was adequate. After performing coronary angiography and confirming eligibility for CABG, the patients' waiting time for surgery ranged from 35.7 to 41.3 days. For all patients, CHD functional class was determined in accordance with the Canadian Cardiology Society and heart failure functional class was determined in accordance with the New York Heart Association. The preoperative risk of death was calculated using the EuroSCORE (European System for Cardiac Operative Risk Evaluation). ${ }^{14}$ CABG surgery was performed on cardiopulmonary bypass with moderate hypothermia $\left(32^{\circ} \mathrm{C}\right)$, with routine cannulation of the ascending aorta and the right atrium via median sternotomy. Heart function was stopped using blood or crystalloid cardioplegia. Bypass most frequently included the anterior interventricular branch of the left coronary artery $(85 \%$ of all interventions). The left internal thoracic artery was mainly used for grafting. The number of coronary arteries with significant disease varied from one to four. Complete revascularization was performed in 26 patients (40\% of all operated patients).

The control group included 65 volunteers (27 women and 38 men), none of whom had CHD. Taking the control group into consideration, we aimed at comparing the research results, not only at baseline (in reference to patients before $\mathrm{CABG}$ ), but especially during the 12-month observation after the surgery.

All subjects were examined using the following questionnaires and scales: a questionnaire including demographic and clinical data, the Nottingham Health Profile (NHP) questionnaire, ${ }^{15}$ the Beck Depression Inventory (BDI), ${ }^{16}$ the Mini-Mental State Examination (MMSE), ${ }^{17}$ a scale for basic assessment of activities of daily (ADL), ${ }^{18}$ and a scale for assessment of instrumental activities of daily living (IADL). ${ }^{19}$

All study patients were examined three times, ie, before CABG and 6 and 12 months after surgery, and at the same time intervals for controls. On each occasion, the questionnaires were filled in by the patients in the presence of the same researcher (EB). Before entry into the study, each subject was informed about its purpose and signed their informed consent. Conduct of the study was approved by the bioethics committee of the Beskidzka Chamber of Physicians in Bielsko-Biała (Resolution 1306/III/99). Details of the questionnaire including demographic and clinical data are shown in Tables 1 and 2. 
Table I General characteristics of study subjects

\begin{tabular}{|c|c|c|c|c|c|c|c|}
\hline & \multicolumn{3}{|c|}{ Patients with CHD } & \multicolumn{3}{|c|}{ Control group } & \multirow{2}{*}{$\begin{array}{l}\text { Statistical } \\
\text { significance } \\
(P)\end{array}$} \\
\hline & $\begin{array}{l}\text { Total } \\
(n=65)\end{array}$ & $\begin{array}{l}\text { Female } \\
(n=29)\end{array}$ & $\begin{array}{l}\text { Male } \\
(n=36)\end{array}$ & $\begin{array}{l}\text { Total } \\
(n=65)\end{array}$ & $\begin{array}{l}\text { Female } \\
(n=38)\end{array}$ & $\begin{array}{l}\text { Male } \\
(n=27)\end{array}$ & \\
\hline Education, n (\%) & & & & & & & 0.97 \\
\hline Elementary & $17(26.2)$ & $8(27.6)$ & $9(25)$ & $15(23.1)$ & $7(18.4)$ & $8(29.6)$ & \\
\hline Vocational & $14(2 \mid .5)$ & $5(17.2)$ & $9(25)$ & $17(26.2)$ & $8(21.1)$ & $9(33.3)$ & \\
\hline Intermediate & $17(26.2)$ & $10(34.5)$ & $7(19.4)$ & $17(26.2)$ & $10(26.3)$ & $7(25.9)$ & \\
\hline High & $17(26.2)$ & $6(20.7)$ & $11(30.6)$ & $16(24.6)$ & $13(34.2)$ & $3(11.1)$ & \\
\hline Place of residence, $n(\%)$ & & & & & & & 0.84 \\
\hline Village & $28(43.1)$ & $13(44.8)$ & I5 (4I.7) & $28(43.1)$ & $16(42.1)$ & $12(44.4)$ & \\
\hline City & $37(56.9)$ & $16(55.2)$ & $21(58.3)$ & $37(52.3)$ & $22(57.9)$ & $15(55.6)$ & \\
\hline Type of work, n (\%) & & & & & & & 0.59 \\
\hline Physical work & $34(52.3 \mathrm{I})$ & $15(5 \mid .7)$ & $19(52.8)$ & $27(4 I .5)$ & $18(47.4)$ & $9(33.3)$ & \\
\hline Intellectual work & $31(47.7)$ & $14(48.3)$ & $17(47.2)$ & $38(58.5)$ & $20(52.6)$ & $18(66.7)$ & \\
\hline Marital status, n (\%) & & & & & & & 0.01 \\
\hline Single & $\mathrm{I}(\mathrm{I} .5)$ & I (3.5) & $0(0)$ & $5(7.7)$ & $4(10.5)$ & I (3.7) & \\
\hline Married & $4 I(63.1)$ & $9(31.0)$ & $32(88.9)$ & $52(80)$ & $31(81.6)$ & $21(77.8)$ & \\
\hline Widowed & $19(29.2)$ & $18(62.1)$ & I (2.8) & $5(7.7)$ & I (2.6) & $4(14.8)$ & \\
\hline Divorced & $4(6.2)$ & I (3.5) & $3(8.3)$ & $3(4.6)$ & $2(5.3)$ & I (3.7) & \\
\hline $\mathrm{BMI}, \mathrm{kg} / \mathrm{m}^{2}($ mean $\pm \mathrm{SD})$ & $29.8 \pm 4.3$ & $31.6 \pm 3.7$ & $28.3 \pm 3.9$ & $26.3 \pm 4.0$ & $26.4 \pm 3.3$ & $26.2 \pm 4.9$ & $<0.001$ \\
\hline Smoking, n (\%) & & & & & & & 0.055 \\
\hline Nonsmoking & $40(6 \mid .5)$ & $22(75.9)$ & $18(50)$ & $49(75.4)$ & $28(73.7)$ & $21(77.8)$ & \\
\hline Smoking & $24(36.9)$ & $7(24.1)$ & $17(47.2)$ & $13(20)$ & $9(23.7)$ & $4(14.8)$ & \\
\hline No data & I (I.5) & 0 & I (2.8) & $3(4.6)$ & I (2.6) & $2(7.4)$ & \\
\hline Employment status, n (\%) & & & & & & & 0.002 \\
\hline Unemployed & $61(93.9)$ & $29(100)$ & $32(88.9)$ & 48 (73.9) & 27 (7I.I) & $21(77.8)$ & \\
\hline Employed & $4(6.2)$ & 0 & $4(11.1)$ & $17(26.2)$ & II (29) & $6(22.2)$ & \\
\hline
\end{tabular}

Abbreviations: BMI, body mass index; CHD, coronary heart disease; SD, standard deviation.

\section{Nottingham Health Profile questionnaire}

The NHP questionnaire was used to examine the QoL of the subjects. The NHP is composed of two parts, ie, a basic component and a complementary component. The basic component includes 38 simple statements covering six dimensions of health-related QoL, ie, physical mobility, energy, pain, sleep, emotional reactions, and social isolation. The complementary component comprises seven individual statements assessing the impact of current health status on the following areas of life: paid employment, performing jobs around the house, social life, personal relationships, sex life, hobbies and interests, and use of leisure time. A Polish adaptation of the NHP questionnaire was created with the consent of its authors. The accuracy and reliability of the Polish adaptation is similar to that of the original version.

\section{Beck Depression Inventory}

The BDI consists of 21 questions, each answer being scored on a scale value of 0 to 3 , depending on the severity of depression. The individual questions of the BDI assess mood, pessimism, sense of failure, self-dissatisfaction, guilt, punishment, selfdislike, self-accusation, suicidal ideas, crying, irritability, social withdrawal, body image, work difficulties, insomnia, fatigue, appetite, weight loss, bodily preoccupation, and loss of libido. Items 1-13 refer to psychological symptoms and items 14-21 refer to more physical symptoms. The following scoring system is used for this scale: $0-11$ points, no depression; $12-26$ points, mild depression; $27-38$ points, moderate depression; and $>38$ points, severe depression.

\section{Mini-Mental State Examination}

The MMSE is a brief questionnaire assessing basic dimensions of cognitive activity, ie, orientation to time and place, registration, attention and calculation, recall of previously remembered information, naming, reading, writing, and performing simple commands, as well as construction apraxia. The maximum number of points a patient can get in this test is 30 .

\section{Activities of Daily Living scale}

The ADL scale consists of six questions referring to the degree of independence in performing activities of daily living, ie, personal hygiene, dressing, using the toilet, sphincter control (urine and stool), eating, and locomotion. 
Table 2 Clinical characteristics of study subjects

\begin{tabular}{|c|c|c|c|c|}
\hline & \multicolumn{3}{|c|}{ Patients with CHD } & \multirow{2}{*}{$\begin{array}{l}\text { Statistical } \\
\text { significance }(P)\end{array}$} \\
\hline & Total $(n=65)$ & Female $(n=29)$ & Male $(n=36)$ & \\
\hline Duration of disease, years & & & & 0.54 \\
\hline$($ mean $\pm S D)$ & $11.3 \pm 8.5$ & $10.6 \pm 9.0$ & $11.9 \pm 8.2$ & \\
\hline Waiting time for surgery (days) & & & & 0.29 \\
\hline (range) & $35.7-41.3$ & $26.3-36.3$ & $41.7-45.4$ & \\
\hline \multicolumn{5}{|l|}{ Symptoms, n (\%) } \\
\hline Dyspnea & $39(60.0)$ & $23(79.3)$ & $16(44.4)$ & 0.02 \\
\hline Chest pain & $49(75.4)$ & $21(72.4)$ & $28(77.8)$ & 0.72 \\
\hline Dizziness & $27(41.5)$ & $17(58.6)$ & $10(27.8)$ & 0.03 \\
\hline Tiredness & $52(80.0)$ & $24(82.7)$ & $28(77.8)$ & 0.74 \\
\hline Functional class CCS, n (\%) & & & & 0.009 \\
\hline I & 0 & 0 & 0 & \\
\hline$\|$ & $20(30.8)$ & $17(47.2)$ & $3(10.3)$ & \\
\hline III & $42(64.6)$ & $18(50)$ & $24(82.8)$ & \\
\hline IV & $3(4.6)$ & $\mathrm{I}(2.8)$ & $2(6.9)$ & \\
\hline Functional class NYHA, n (\%) & & & & 0.02 \\
\hline 1 & $3(4.6)$ & $\mathrm{I}(2.8)$ & $2(6.9)$ & \\
\hline ॥ & $18(27.7)$ & $16(44.4)$ & $2(6.9)$ & \\
\hline II & $42(64.6)$ & $18(50)$ & $24(82.8)$ & \\
\hline IV & $2(3.1)$ & $\mathrm{I}(2.8)$ & I (3.4) & \\
\hline Coronary artery bypass grafts, $\mathrm{n}(\%)$ & & & & 0.93 \\
\hline 1 & $10(15.4)$ & $7(24.1)$ & $3(13.9)$ & \\
\hline 2 & $28(43.1)$ & $10(34.5)$ & $18(50)$ & \\
\hline 3 & $23(35.4)$ & $10(34.5)$ & $13(36.1)$ & \\
\hline 4 & $4(3.1)$ & $2(6.9)$ & $2(3.1)$ & \\
\hline \multicolumn{5}{|l|}{ Types of grafts, n (\%) } \\
\hline Venous & $10(15.4)$ & $3(10.3)$ & $7(19.4)$ & 0.94 \\
\hline Arterial & $32(49.2)$ & II (37.9) & $21(58.3)$ & 0.99 \\
\hline Venoarterial & $23(35.4)$ & $15(51.7)$ & $8(22.2)$ & 0.04 \\
\hline EuroSCORE (mean $\pm S D)$ & $2.5 \pm 1$ & $3 \pm 0.9$ & $2.1 \pm 0.8$ & $<0.00 \mathrm{I}$ \\
\hline \multicolumn{5}{|c|}{ Duration of postoperative wound pain, $\mathrm{n}(\%)$} \\
\hline Up to a week & $3(4.7)$ & $2(6.9)$ & I (2.9) & 0.77 \\
\hline 2 weeks & $9(14.1)$ & $3(10.3)$ & $6(17.1)$ & 0.79 \\
\hline I month & $10(15.6)$ & $8(27.6)$ & $2(5.7)$ & 0.51 \\
\hline Over a month & $42(65.6)$ & $16(55.2)$ & $26(74.3)$ & 0.2 \\
\hline \multicolumn{5}{|l|}{ Feeling after surgery } \\
\hline I feel much worse & $2(3.1)$ & 0 & $2(5.7)$ & - \\
\hline No significant difference & $2(3.1)$ & $2(6.9)$ & 0 & - \\
\hline I feel better & $43(67.2)$ & $21(72.4)$ & $22(62.9)$ & 0.51 \\
\hline I changed my current lifestyle & $17(26.6)$ & $6(20.7)$ & II (3I.4) & 0.64 \\
\hline
\end{tabular}

Abbreviations: CHD, coronary heart disease; SD, standard deviation; CCS, Canadian Cardiology Society; NYHA, New York Heart Association.

\section{Instrumental Activities}

\section{of Daily Living scale}

The IADL scale assesses eight functional parameters, including ability to use a telephone, do shopping, prepare meals, do housework, do the washing, use transport, take medications, and manage money.

\section{Statistical analysis}

Statistica 9.0 PL software (StatSoft Inc., Tulsa, OK, USA) was used for statistical testing of the data obtained. The mean and standard deviation were determined in the first stage of the statistical evaluation for characteristics expressed on an interval scale. Due to the type of characteristics evaluated in the statistical analysis, the following tests were used: the chisquared test for independence, the Pearson product-moment correlation coefficient between two variables, analysis of variance, the Mann-Whitney $U$ test, and the $Z$-test (a version of the Student's $t$-test). The level of statistical significance was set at $P<0.05$.

\section{Results}

The general characteristics of the subjects are shown in Table 1 and their clinical characteristics are shown in Table 2. Patients with CHD were significantly older 
$(P<0.01)$ and had a higher body mass index $(P<0.001)$ than the controls. In terms of comorbidities, the patients with CHD had significantly higher rates of diabetes $(P<0.01)$ and hypercholesterolemia $(P<0.001)$ than the controls (Table 3). Most of the CABG interventions involved creation of two or three grafts, mainly arterial or arteriovenous (Table 2).

\section{Quality of life}

In male $\mathrm{CABG}$ patients, QoL domain scores before surgery were lower than after surgery and lower than in the control group (Figure 1). Despite the level of emotional reactions being significantly improved following $\mathrm{CABG}$, it still did not reach the values in the control group. Further, in female $\mathrm{CABG}$ patients, the domains evaluated were unfavorable before surgery and significantly improved following CABG, but did not normalize (except for pain and social isolation) to the level of the control group. Values for the QoL domains were similar for both sexes in the $\mathrm{CABG}$ group before surgery. Following $\mathrm{CABG}$, the energy, sleep, and physical mobility domains improved in different ways according to gender and were more favorable in men than in women (Figure 1).

\section{Beck Depression Inventory}

The severity of depression in the studied patients suffering from CHD was greater before than after the CABG surgery. In men the level of depression improved and reached the level of the control group, whereas in women it did not (Figure 2). The estimated severity of depression before CABG was similar between women and men and improved after $\mathrm{CABG}$, with the improvement being greater in men than in women (Figure 2).

\section{Mini-Mental State Examination}

The level of cognitive function before CABG was similar between women and men and was lower than in the control group (Figure 2). Following CABG, the level of cognitive functioning improved and normalized in men by 6 months after surgery and in women by 12 months after surgery. Changes in the level of cognitive functioning following surgical treatment of CHD were similar between women and men (Figure 2).

\section{Activities of Daily Living scale}

The study patients with CHD reported that they had had difficulty performing basic activities of daily living before surgery, and this was confirmed by their lower scores on the ADL assessment scale compared with controls. Following $\mathrm{CABG}$, a significant improvement in performance of these activities was seen in all study patients with CHD (Figure 3 ). Nevertheless, unlike men, women did not regain the level of independence seen for women in the control group (Figure 3). Men reported a greater degree of independence than women 6 months after CABG, with $69 \%$ of men versus $28 \%$ of women reporting that they could perform activities of daily living independently. It is worth noting that both women and men experienced near complete disappearance of their significant disability by 6 months after CABG (Figure 3 ).

\section{Instrumental Activities of Daily Living scale}

Before $\mathrm{CABG}$, significant impairment in ability to perform IADL was observed in the patients with CHD compared with controls (Figure 3), with greater impairment seen in women than in men. Following surgical treatment of CHD, significant improvement in IADL was found one year after CABG in men only (Figure 3). Twenty-four percent of women and

Table 3 Comorbidity in study subjects

\begin{tabular}{|c|c|c|c|c|c|c|c|}
\hline \multirow[t]{2}{*}{ Comorbidities, n (\%) } & \multicolumn{3}{|c|}{ Patients with CHD } & \multicolumn{3}{|c|}{ Control group } & \multirow{2}{*}{$\begin{array}{l}\text { Statistical } \\
\text { significance }(P)\end{array}$} \\
\hline & $\begin{array}{l}\text { Total } \\
(n=65)\end{array}$ & $\begin{array}{l}\text { Female } \\
(n=29)\end{array}$ & $\begin{array}{l}\text { Male } \\
(n=36)\end{array}$ & $\begin{array}{l}\text { Total } \\
(n=5)\end{array}$ & $\begin{array}{l}\text { Female } \\
(n=38)\end{array}$ & $\begin{array}{l}\text { Male } \\
(n=27)\end{array}$ & \\
\hline $\begin{array}{l}\text { Myocardial infarction } \\
\text { in medical history }\end{array}$ & $65(100)$ & $29(100)$ & $36(100)$ & 0 & 0 & 0 & - \\
\hline Hypertension & $53(81.5)$ & $24(82.8)$ & $29(80.6)$ & 0 & 0 & 0 & - \\
\hline Hypercholesterolemia & $65(100)$ & $29(100)$ & $36(100)$ & $\mid 4(2 \mid .5)$ & $7(25.9)$ & $7(18.4)$ & $<0.001$ \\
\hline Diabetes mellitus & $23(35.4)$ & $10(34.5)$ & $13(36.1)$ & $3(4.6)$ & 0 & $3(7.9)$ & 0.002 \\
\hline Orthopedic diseases & $2(3.1)$ & $2(6.9)$ & 0 & 0 & 0 & 0 & - \\
\hline Neurologic diseases & I (I.5) & 0 & I (2.8) & 0 & 0 & 0 & - \\
\hline Kidney diseases & $3(4.6)$ & $3(10.3)$ & 0 & $2(3.1)$ & $2(7.4)$ & 0 & 0.88 \\
\hline Respiratory system diseases & $9(13.8)$ & $4(13.8)$ & $5(13.9)$ & $4(6.2)$ & $2(7.4)$ & $2(5.3)$ & 0.88 \\
\hline Digestive system diseases & $7(10.8)$ & $3(10.3)$ & $4(\mathrm{II} . \mathrm{I})$ & $2(3.1)$ & I (3.7) & I (2.6) & 0.45 \\
\hline Rheumatic diseases & $15(23.1)$ & $9(31)$ & $6(16.7)$ & $8(12.3)$ & $6(22.2)$ & $2(5.3)$ & 0.29 \\
\hline
\end{tabular}

Abbreviation: CHD, coronary heart disease. 

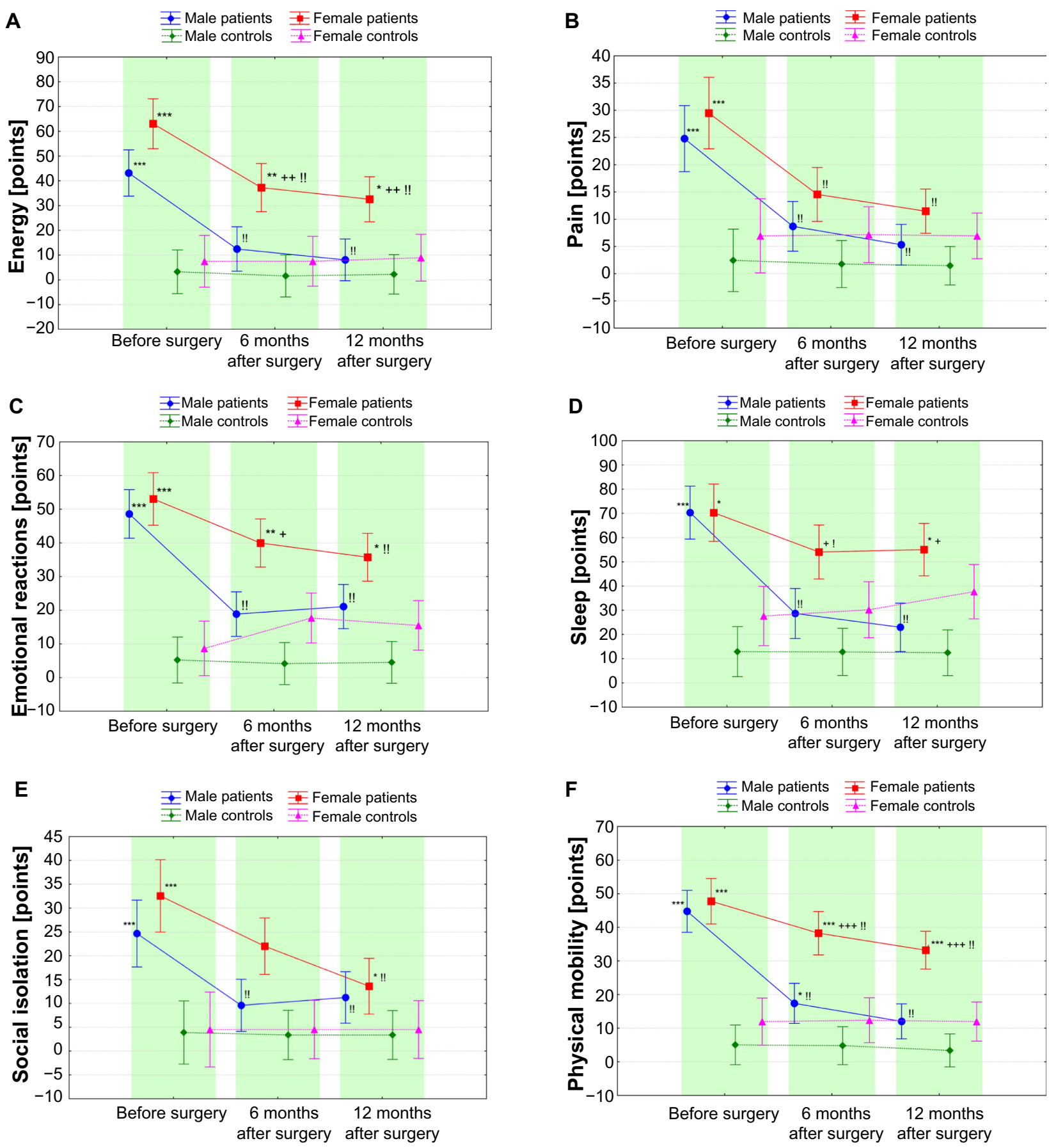

Figure I Health dimensions of energy $(\mathbf{A})$, pain $(\mathbf{B})$, emotional reactions $(\mathbf{C})$, sleep $(\mathbf{D})$, social isolation $(\mathbf{E})$, and physical mobility $(\mathbf{F})$ in patients with $\mathbf{C H D}$ before $(0)$ and 6 and I 2 months after CABG and in the control group. Values shown are mean \pm SD. ${ }^{*} P<0.05,{ }^{* *} P<0.0 \mathrm{I},{ }^{* * *} P<0.00 \mathrm{I}$ versus controls; ${ }^{+} P<0.05,{ }^{++} P<0.00 \mathrm{I},{ }^{++} P<0.00 \mathrm{I}$ versus men; $: P<0.05$, " $P<0.00$ I versus 0 .

Abbreviations: $\mathrm{CABG}$, coronary artery bypass grafting; $\mathrm{CHD}$, coronary heart disease; SD, standard deviation.

$33 \%$ of men reported overall efficiency in performing IADL before $\mathrm{CABG}$ surgery; a year after surgery, these figures increased to $31 \%$ and $64 \%$, respectively.

\section{Correlational analysis}

The results of correlational analysis for the domains of $\mathrm{QoL}$ and BDI, MMSE, ADL, and IADL in patients with CHD are shown in Table 4. In the men, the values for nearly all domains of the QoL showed a significantly positive correlation with the level of depression (at all assessment points) and a negative correlation with values for ADL and IADL before CABG, and 6 months after surgery $(P<0.05-0.001$, Table 4). Patients from this group showed no correlation between QoL domain scores and level of cognitive function 

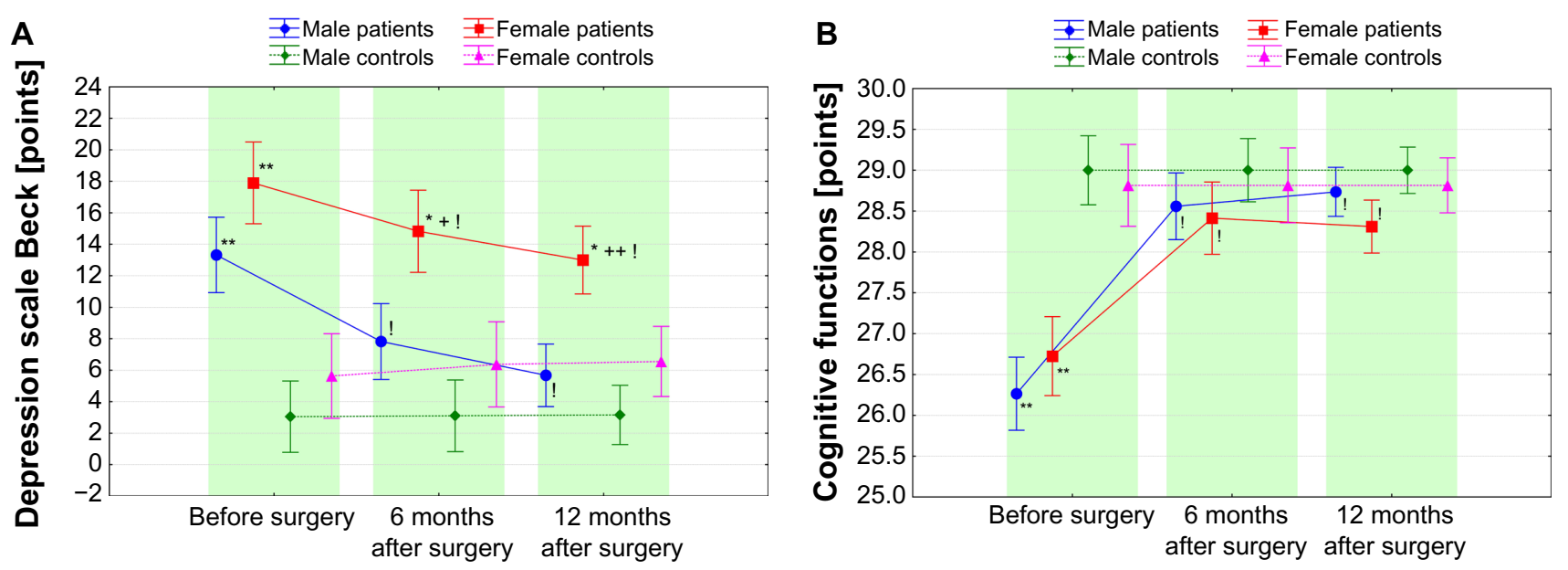

Figure 2 Level of depression (A) and cognitive function (B) in patients with CHD before $(0)$ and 6 and 12 months after CABG and in the control group. Values are shown as the mean \pm SD. ${ }^{*} P<0.05$, ${ }^{* *} P<0.00$ I versus controls; ${ }^{+} P<0.05,{ }^{++} P<0.00$ I versus men; $P<0.00$ I versus 0 .

Abbreviations: $C A B G$, coronary artery bypass grafting; $C H D$, coronary heart disease; SD, standard deviation.

(Table 4). The scope and direction of the significance of correlations between the abovementioned indicators in female patients were similar to those in male patients (Table 4).

\section{Discussion}

In this study, QoL was diminished in elderly patients with $\mathrm{CHD}$, but as a result of CABG there was significant improvement in all QoL domains by 6 and 12 months after surgery, with normalization (except for emotional reactions in men, and energy, emotional reactions, sleep, and physical mobility in women) to the levels observed in the control group.

The results of this study are consistent with the findings of other authors. Peric et $\mathrm{al}^{7}$ examined QoL using the NHP in nearly 250 patients undergoing CABG surgery. They observed that low QoL before CABG improved 6 months after surgery. Ma et $\mathrm{al}^{8}$ evaluated QoL using the NHP questionnaire in nearly 300 patients undergoing $\mathrm{CABG}$, and a follow-up study conducted 5 years post-surgery showed significant improvement in QoL, especially in the areas of social isolation and physical mobility. Due to the much longer time interval since surgical treatment of CHD in their study compared with ours and in view of the Chinese study population, the results obtained for QoL in that study cannot be directly compared with the results of the present work. Graham et $\mathrm{al}^{5}$ evaluated QoL in elderly patients after CABG. Four years after surgery, the patients had better health status and better QoL than those who did not undergo revascularization. These results justify the eligibility of elderly patients
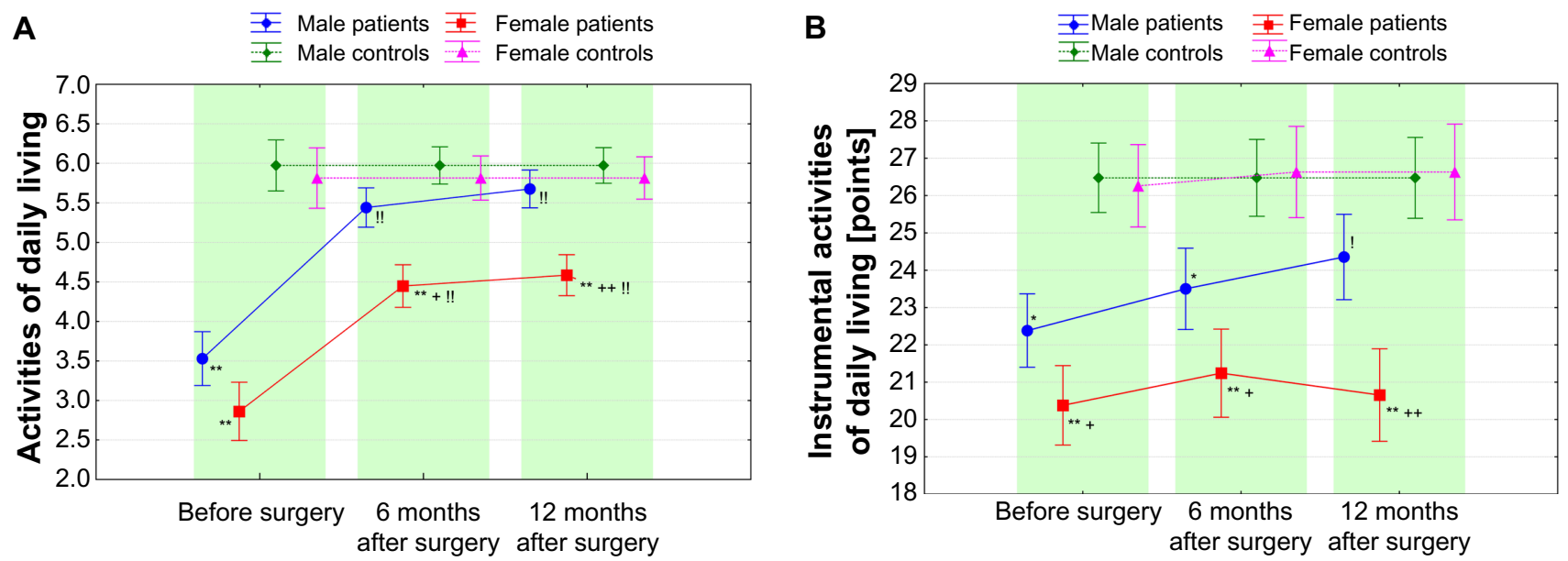

Figure 3 Value of basic (ADL) (A) and instrumental (IADL) (B) activities of daily living in patients with CHD before (0) and after 6 and 12 months from CABG and in the control group. Values are shown as the mean \pm SD. ${ }^{+} P<0.05,+P<0.00$ I versus controls; ${ }^{+} P<0.05,+P<0.00$ I versus men; $P<0.05$, " $P<0.00$ I versus 0 .

Abbreviations: ADL, Basic Activities of Daily Living scale; CABG, coronary artery bypass grafting; CHD, coronary heart disease; IADL, Instrumental Activities of Daily Living scale; SD, standard deviation. 
Table 4 Correlation coefficients between domains of QoL and level of depression and cognitive function and performing basic and instrumental activities of daily living in patients with CHD before and after CABG

\begin{tabular}{|c|c|c|c|c|c|c|c|c|c|c|c|c|}
\hline \multirow{2}{*}{$\begin{array}{l}\text { Quality of } \\
\text { life domain }\end{array}$} & \multicolumn{3}{|l|}{ BDI } & \multicolumn{3}{|l|}{ MMSE } & \multicolumn{3}{|l|}{ ADL } & \multicolumn{3}{|l|}{ IADL } \\
\hline & $\begin{array}{l}\text { Pre- } \\
\text { CABG }\end{array}$ & $\begin{array}{l}\text { Post } 6 \\
\text { months }\end{array}$ & $\begin{array}{l}\text { Post } 12 \\
\text { months }\end{array}$ & $\begin{array}{l}\text { Pre- } \\
\text { CABG }\end{array}$ & $\begin{array}{l}\text { Post } 6 \\
\text { months }\end{array}$ & $\begin{array}{l}\text { Post } 12 \\
\text { months }\end{array}$ & $\begin{array}{l}\text { Pre- } \\
\text { CABG }\end{array}$ & $\begin{array}{l}\text { Post } 6 \\
\text { months }\end{array}$ & $\begin{array}{l}\text { Post I2 } \\
\text { months }\end{array}$ & $\begin{array}{l}\text { Pre- } \\
\text { CABG }\end{array}$ & $\begin{array}{l}\text { Post } 6 \\
\text { months }\end{array}$ & $\begin{array}{l}\text { Post } 12 \\
\text { months }\end{array}$ \\
\hline \multicolumn{13}{|l|}{ Energy } \\
\hline M & $0.49^{\dagger}$ & $0.77^{\ddagger}$ & $0.68^{\ddagger}$ & -0.10 & -0.18 & 0.08 & $-0.55^{\ddagger}$ & $-0.40^{\dagger}$ & -0.21 & $-0.63^{\ddagger}$ & -0.17 & 0.01 \\
\hline $\mathrm{F}$ & $0.50^{\dagger}$ & $0.60^{\ddagger}$ & $0.64^{\ddagger}$ & -0.11 & 0.21 & -0.32 & $-0.7 I^{\ddagger}$ & $-0.42^{*}$ & $-0.42^{*}$ & $-0.52^{\dagger}$ & -0.35 & $-0.42 *$ \\
\hline \multicolumn{13}{|l|}{ Pain } \\
\hline M & $0.53^{\ddagger}$ & $0.72^{\ddagger}$ & $0.65^{\ddagger}$ & 0.02 & -0.05 & 0.09 & $-0.34 *$ & $-0.37^{*}$ & -0.29 & -0.22 & $-0.37^{*}$ & 0.05 \\
\hline $\mathrm{F}$ & 0.34 & $0.47^{\dagger}$ & $0.52^{\dagger}$ & 0.04 & -0.02 & -0.25 & $-0.37^{*}$ & $-0.50^{\dagger}$ & -0.29 & $-0.45^{*}$ & 0.06 & -0.32 \\
\hline \multicolumn{13}{|c|}{ Emotional reaction } \\
\hline$M$ & $0.76^{\ddagger}$ & $0.7 I^{\ddagger}$ & $0.82^{\ddagger}$ & 0.01 & -0.19 & 0.21 & $-0.59^{\ddagger}$ & -0.13 & -0.08 & $-0.59^{\ddagger}$ & -0.19 & 0.14 \\
\hline$F$ & $0.50^{\dagger}$ & $0.53^{\dagger}$ & $0.53^{\dagger}$ & -0.16 & 0.25 & $-0.50^{\dagger}$ & $-0.69 \ddagger$ & $-0.67^{\ddagger}$ & $-0.46^{\dagger}$ & -0.32 & -0.26 & -0.18 \\
\hline \multicolumn{13}{|l|}{ Sleep } \\
\hline M & $0.48^{\dagger}$ & $0.35^{*}$ & $0.52^{\ddagger}$ & -0.23 & -0.01 & -0.19 & $0.53^{\ddagger}$ & -0.19 & -0.08 & $-0.48^{\dagger}$ & -0.01 & -0.10 \\
\hline $\mathrm{F}$ & $0.44^{*}$ & 0.34 & 0.24 & -0.17 & 0.02 & $-0.39 *$ & $-0.44 *$ & $-0.52^{\dagger}$ & -0.29 & $-0.43 *$ & 0.04 & 0.02 \\
\hline \multicolumn{13}{|l|}{ Social isolation } \\
\hline M & $0.54^{\ddagger}$ & $0.76^{\ddagger}$ & $0.49^{\dagger}$ & 0.11 & $-0.36^{*}$ & 0.12 & $-0.48^{\dagger}$ & -0.27 & -0.02 & $-0.33^{*}$ & -0.06 & 0.19 \\
\hline $\mathrm{F}$ & 0.26 & $0.38^{*}$ & 0.16 & 0.01 & -0.13 & $-0.50^{\dagger}$ & -0.35 & $-0.59 \ddagger$ & -0.20 & $-0.45^{*}$ & 0.07 & 0.01 \\
\hline \multicolumn{13}{|c|}{ Physical mobility } \\
\hline$M$ & 0.25 & $0.60^{\ddagger}$ & $0.68^{\ddagger}$ & -0.16 & 0.00 & 0.17 & $-0.5 \mathrm{I}^{\dagger}$ & $-0.50^{\dagger}$ & -0.19 & $-0.47^{\dagger}$ & -0.10 & 0.05 \\
\hline $\mathrm{F}$ & 0.34 & $0.60^{\ddagger}$ & $0.67^{\ddagger}$ & -0.23 & 0.01 & $-0.47^{\dagger}$ & $-0.57^{\ddagger}$ & $-0.69^{\ddagger}$ & $-0.68^{\ddagger}$ & $-0.6 I^{\ddagger}$ & -0.30 & -0.32 \\
\hline
\end{tabular}

Notes: $* P<0.05 ;{ }^{\dagger} P<0.01 ;{ }^{\ddagger} P<0.001$.

Abbreviations: CABG, coronary artery bypass grafting; CHD, coronary heart disease; M, male; F, female; BDI, Beck Depression Inventory; MMSE, Mini-Mental State Examination; ADL, Activities of Daily Living; IADL, Instrumental Activities of Daily Living; QoL, quality of life; SD, standard deviation.

for CABG surgery. In 137 postmenopausal women, levels of QoL examined 0-12 (mean 4.6) months before CABG and 6-18 (mean 11.5) months after surgery were comparable in statistical analysis. ${ }^{20}$ However, in about half of the women examined, it appeared that there were changes in QoL after CABG surgery, including improvement or deterioration in equal amounts. These differences may be due at least in part to the wide range of time intervals between the initial and final assessments.

In our study, improvement in QoL after CABG surgery differed according to subject gender, despite the fact that QoL domain scores were similar for men and women prior to surgery. Monitoring of QoL at 6 and 12 months after CABG surgery indicated that domains such as energy, sleep, and physical mobility did not normalize in women after CABG surgery, but normalized rapidly in all domains except for emotional reactions in men.

The results and experience gleaned from personal contact with the patients indicates that the women had poorer QoL in the field of physical mobility. Women were more likely than men to complain about limitations in performing ADL and IADL and about sleep disorders, which probably contributed to their lower reported QoL. This raises the question of what efforts should be made in order to achieve greater improvement of QoL in women during the recovery period after CABG surgery. Achieving better welfare is possible thanks to the support provided for the women by the medical staff. It has already been shown that when such support is provided for patients awaiting CABG surgery, it is highly beneficial for their well-being and QoL. ${ }^{21}$ In a randomized study described by McHugh et $\mathrm{a}^{21}$ a cardiac nurse held a series of educational meetings for patients awaiting CABG surgery. This training was held in the patient's home or at the family doctor's office. It included explaining to the patient the purpose and the course of the surgery, the need and the time of hospitalization, and the necessity for convalescence. Before these patients underwent cardiac surgery, they had undergone coronary angiography and been put on a waiting list, in a manner similar to that described by Ciccone et al. ${ }^{22}$ The waiting time before surgery can be used for appropriate education (with elements of psychiatry), preparing the patient for surgery in accordance with the model proposed by Ciccone et al, ${ }^{23}$ and emphasizing the role of the nurse in improving QoL for patients with heart failure. McHugh et $\mathrm{l}^{21}$ reported that training not only improved well-being and mood, but also resulted in a quantitative and qualitative reduction of CHD risk factors, such as smoking, body mass index, cholesterol concentrations, physical activity, and arterial blood pressure. 
The results of correlational studies in patients with CHD indicate a significant association between QoL, degree of depression, and ability to perform basic activities of daily living. Using the BDI, we identified symptoms of depression in patients with CHD, especially women. It has been observed that the depression symptoms improved in men 6 months after CABG surgery but in women the improvement of these symptoms was visible after a longer period. McCrone et $\mathrm{al}^{24}$ reported similar findings, demonstrating that the depression in patients with CHD was more severe in women than in men. These researchers found a relationship between the severity of depression and time elapsed since CABG surgery. Depression appeared 2-3 days after CABG and a return to the preoperative level occurred approximately 4 weeks after surgery. Research by King et $\mathrm{al}^{25}$ showed no significant difference in the severity of depression between women and men undergoing CABG surgery; however, mild depression was present for 6 months following surgery. The severity of depression can be reduced by providing psychotherapy before CABG surgery. ${ }^{21}$ The research available shows that episodes of depression in patients suffering from CHD undergoing cardiac treatment increases the risk of morbidity and mortality. ${ }^{12,13}$ Rates of major depressive disorder of around $15 \%$ have been reported in patients post myocardial infarction or $\mathrm{CABG}$. The prevalence of depression has been reported to be high in patients with CHD and to have a significant impact on QoL. ${ }^{26}$ We have shown mild cognitive impairment but no signs of dementia before $\mathrm{CABG}$ surgery in patients suffering from CHD. Factors that may contribute to this phenomenon are older patient age, brain hypoxia, and depression. The cognitive impairment seen in our patients was reversible, with almost no disturbance of cognitive function seen in either women or men 6 months after cardiac surgery. Phillips-Bute et $\mathrm{al}^{27}$ have also evaluated impairment of cognitive function in patients with CHD undergoing CABG surgery. This group showed that cognitive function was impaired in $41 \%$ of patients 6 weeks after CABG surgery and in about $37 \%$ of patients at 12 months. The authors suggest that cognitive function and $\mathrm{QoL}$ are connected, concluding that unsatisfactory recovery from cognitive impairment in patients after CABG may limit improvement in QoL for these people. Our research indicates a significant correlation between QoL domain scores and the level of cognitive function in women one year after CABG surgery.

It is known that one of the most important factors determining well-being is adequate physical mobility, especially the ability to perform activities of daily living. In our research, patients with CHD reported difficulties in performing basic activities before $\mathrm{CABG}$, which made them significantly different from the control group. After cardiac surgery, the range of simple activities of daily living improved in both women and men. Men had a higher degree of independence in activities of daily living than women 6 and 12 months after CABG surgery; however, recovery from impaired mobility was similar in both men and women and normalization was evident 6 months after surgery. Mobility in the field of IADL was significantly impaired before $\mathrm{CABG}$, with greater impairment seen in women. Following $\mathrm{CABG}$, men showed improvement in IADL, while women showed impairment in these activities throughout the entire study period. IADL in patients treated with CABG was investigated by Phillips-Bute et al, ${ }^{27}$ who showed significant impairment in performance of these activities before surgery and invariably after one year. However, it should be noted that Phillips-Bute et al did not report details of quantitative participation of women and men in their study.

It is fair to note some deficiencies in our work. These include the small number of patients enrolled in the studies, undergoing a planned CABG surgery only with stable CHD. It may be assumed that the results of QoL, mental efficiency, and physical mobility studies would be less favorable in patients with unstable CHD, more severe heart failure, and those undergoing emergency coronary revascularization. Another shortcoming of our study is that rehabilitation and psychological procedures used in patients during the postoperative period were not considered. Gathering reliable information on this procedure was impossible. Use of an appropriate program for physical and mental rehabilitation could contribute to obtaining greater improvement, as has been shown elsewhere. ${ }^{28}$ It appears that doing research into the well-being and the physical fitness of patients after CABG in the several years following surgery would contribute to investigating the long-term effectiveness of revascularization. Other authors ${ }^{7}$ have monitored QoL in their patients for up to 5 years after surgical coronary revascularization. Another interesting issue would be to compare QoL following coronary revascularization via $\mathrm{CABG}$ or percutaneous coronary intervention.

This study demonstrates that performing $\mathrm{CABG}$ in the elderly is associated with significant improvements in healthrelated QoL. The data presented here support the use of the NHP questionnaire to obtain a comprehensive QoL assessment in elderly patients. The results of correlation studies suggest the existence of relationships between the level of QoL and the severity of depression in patients suffering from CHD. These relationships are independent of when the research is conducted 
(ie, before or after CABG) and independent of the effect of limitations in activities of daily living on QoL, especially before surgery and 6 months afterwards. The level of QoL appears not to have any relationship with cognitive functioning, at least before surgery and 6 months after surgery, with the exception of women, in whom the level of cognitive function shows a positive correlation with scores on some QoL domains (emotional reaction, social isolation, physical mobility, and sleep) one year after CABG. Further prospective randomized trials utilizing advanced analytical techniques to assess health-related QoL outcomes, especially in relation to depression and activities of daily living, are urgently needed.

\section{Conclusion}

Elderly patients with CHD have decreased QoL, which improves following CABG in women and normalizes in men. Surgical revascularization of the coronary arteries in patients with CHD decreases depression and improves the ability to perform basic activities of daily living.

\section{Acknowledgments}

The authors extend their sincere thanks to the Director of the Department of Cardiovascular Surgery and Transplantology, Jagiellonian University Medical College, Krakow, Poland, for giving permission to conduct this research, and also to the patients, without whom this work could not have been done.

\section{Disclosure}

The authors report no conflicts of interest in this work.

\section{References}

1. Heidenreich PA, Trogdon JG, Khavjon OA, et al. Forecasting the future of cardiovascular disease in the United States: a policy statement from the American Association. Circulation. 2011;123:933-944.

2. Lloyd-Jones DM, Hong Y, Labarthe D, et al. Defining and setting national goals for cardiovascular health promotion and disease reduction: the American Heart Association's strategic impact goal through 2020 and beyond. Circulation. 2010;121:586-613.

3. Poloński L, Gạsior M, Gierlotka M. [Polish Registry of Acute Coronary Syndromes (PL-ACS). Characteristics treatments and outcomes of patients with acute coronary syndromes in Poland]. Kardiol Pol. 2007;65: 861-872. Polish.

4. Hiro T, Kimura T, Morimoto T, et al. Diabetes mellitus is a major negative determinant of coronary plaque regression during statin therapy in patients with acute coronary syndrome. Circ J. 2010;74:1165-1174.

5. Graham MM, Norris CM, Galbraith PD, Knudtson ML, Ghail WA. Quality of life after coronary revascularization in the elderly. Eur Heart J. 2006;27:1690-1698.

6. Kamiya M, Takayama M, Takano H, et al. Clinical outcome and quality of life of octogenarian patients following percutaneous coronary intervention or surgical coronary revascularization. Circ J. 2007;71:847-854.
7. Peric V. Quality of life in patients related to gender differences before and after coronary artery bypass surgery. Interact Cardiovasc Thorac Surg. 2010;10:232-238.

8. Ma CM, Chen Y, Xie JY, Wan F. [Quality of life five years after coronary artery bypass graft]. Zhonghua Xin Xue Guan Bing Za Zhi. 2008;36:123-127. Chinese.

9. Miller CL. Symptom reflections of women with cardiac disease and advanced practice nurses: a descriptive study. Prog Cardiovasc Nurs. 2003;18:69-76.

10. Baig K, Harling L, Papanikitas J, et al. Does coronary artery bypass grafting improve quality of life in elderly patients? Interact CardioVasc Thorac Surg. 2013;17:542-553.

11. Henk F, van Stel HF, Buskens E. Comparison of the SF-6D and EQ-5D in patients with coronary heart disease. Health Qual Life Outcomes. 2006;4:1-9.

12. Tully PJ. Psychological depression and cardiac surgery: a comprehensive review. J Extra Corpor Technol. 2012;44:224-232.

13. Tully PJ, Baker RA. Depression, anxiety, and cardiac morbidity outcomes after coronary artery bypass surgery: a contemporary and practical review. J Geriatr Cardiol. 2012;9:197-208.

14. Nashef SA, Roques F, Michel P, Gauducheau E, Lemeshow S, Salamon R. European system for cardiac operative risk evaluation (EuroSCORE). Eur J Cardiothorac Surg. 1999;16:9-13.

15. Hunt SM, Mc Kenna SP, McEwen J, Papp E. Nottingham Health Profile: subjective health status and medical consultations. Soc Sci Med. 1981; 15 Pt 1:221-229.

16. Beck AT, Ward CH. An inventory for measuring depression. Arch Gen Psychiatry. 1961;4:53-63.

17. Folstein MF, Folstein SE, McHugh PR. "Mini-mental state". A practical method for grading the cognitive state of patients for the clinician. J Psychiatr Res. 1975;12:189-198.

18. Katz S, Dovns TD, Cash HR. Progress in development of the index of ADL. Gerontologist. 1970;10:20-30.

19. Lawton M. A research and service-oriented multilevel assessment instrument. J Gerontol. 1982;37:91-99.

20. Covinsky KE, Lin F, Bittner V, Hlatky MA, Knight SJ, Vittinghoff E. Health-related quality of life following coronary artery bypass graft surgery in post-menopausal women. J Gen Intern Med. 2008;23: 1429-1434.

21. McHugh F, Lindsay G, Hanlon P. Nurse led shared care of patients on the waiting list for coronary artery bypass surgery: a randomised controlled trial. Heart. 2001;86:317-323.

22. Ciccone MM, Aquilino A, Frasso G, et al. Waiting lists in coronary artery bypass graft patients and role of coronary angiography: the Apulian experience. Clinical Audit. 2013;5:49-55.

23. Ciccone MM, Aquilino A, Cortese F, et al. Feasibility and effectiveness of a disease and care management model in the primary health care system for patients with heart failure and diabetes (Project Leonardo). Vasc Health Risk Manag. 2010;6:297-305.

24. McCrone S, Lenz E, Tarian A. Anxiety and depression incidence and patterns in patients after coronary artery bypass graft surgery. Appl Nurs Res. 2001;14:155-164.

25. King KB. Emotional and functional outcomes in women with coronary heart disease. J Cardiovasc Nurs. 2001;15:54-70.

26. Colquhoun DM, Bunker SJ, Clarke DM, et al. Screening, referral and treatment for depression in patients with coronary heart disease. Med J Aust. 2013;198:483-484.

27. Phillips-Bute B, Mathew JP, Blumenthal JA, et al. Association of neurocognitive function and quality of life 1 year after coronary artery bypass (CABG) surgery. Psychosom Med. 2006;68:369-375.

28. Koivunen K. Rehabilitation and guidance as reported by women and men who had undergone coronary bypass surgery. J Clin Nurs. 2007;16: 688-697. 
Patient Preference and Adherence

Dovepress

\section{Publish your work in this journal}

Patient Preference and Adherence is an international, peer-reviewed, open access journal focusing on the growing importance of patient preference and adherence throughout the therapeutic continuum. Patient satisfaction, acceptability, quality of life, compliance, persistence and their role in developing new therapeutic modalities and compounds to optimize clinical outcomes for existing disease states are major areas of interest. This journal has been accepted for indexing on PubMed Central. The manuscript management system is completely online and includes a very quick and fair peer-review system. Visit http://www.dovepress.com/ testimonials.php to read real quotes from published authors.

Submit your manuscript here: http://www.dovepress.com/patient-preference-and-adherence-journal 